\title{
Subtype-selective Cholecystokinin Receptor Antagonists Block Cholecystokinin Modulation of Dopamine-mediated Behaviors in the Rat Mesolimbic Pathway
}

\author{
Jacqueline N. Crawley \\ Unit on Behavioral Neuropharmacology, Experimental Therapeutics Branch, National Institute of Mental Health, Bethesda, \\ Maryland 20892
}

Subtype-selective antagonists of the peripheral-type (CCKA) and the central-type (CCK-B) cholecystokinin (CCK) receptors were employed to determine the receptor subtype(s) mediating the modulatory actions of CCK on dopamine-induced changes in exploratory activity at three sites in the mesolimbic pathway of the rat. The CCK-A antagonist L364,718 (10 $\mathrm{ng}$ ) blocked CCK potentiation of dopamine-induced hyperlocomotion in the medial posterior nucleus accumbens. The CCK-B antagonist $\mathrm{Cl}-988(20 \mathrm{ng})$ blocked CCK inhibition of dopamine-induced hyperlocomotion in the anterior nucleus accumbens. The CCK-B antagonists $\mathrm{Cl}-988$ (20 ng) and L-365,260 (10 ng) blocked CCK potentiation of dopamine-induced hypolocomotion in the ventral tegmental area. These data indicate a CCK-B pharmacology in the cell body and anterior terminal field, and a CCK-A pharmacology in the posterior terminal field, of the mesolimbic dopamine pathway.

Behavioral analyses using the selective CCK antagonists did not detect a contribution of endogenous CCK to exploratory locomotion. L-364,718 (10 $\mathrm{ng}$ ), L-365,260 (10 $\mathrm{ng}$ ), and Cl-988 (20 ng or $2 \mu \mathrm{g}$ ), microinjected into the medial posterior nucleus accumbens, anterior nucleus accumbens, or ventral tegmental area, had no effect on baseline exploratory locomotion or on dopamine-induced changes in exploratory locomotion. Using a dark-induced hyperlocomotion paradigm, the CCK antagonists at these doses at these sites and intraperitoneally had no effect on the high levels of exploratory locomotor activity exhibited by the rats in the dark testing environment, or the lower levels of exploratory activity in the lighted environment. Endogenous CCK may not be released during dopamine-induced hyperlocomotion or dark-induced hyperlocomotion, or endogenous CCK may not contribute significantly to exploratory behaviors mediated through the mesolimbic dopamine pathway. Utilization of

Received Jan. 7. 1992: revised Mar. 24, 1992; accepted Mar. 31, 1992.

Excellent technical assistance was provided by Ms. Marie Potter, Mr. John Evers, and Mr. Gabe Hodziewich in conducting portions of the behavioral testing of intraperitoneal CCK antagonists in the dark-induced hyperlocomotion paradigm, by Ms. Sue Fiske in conducting a portion of the ventral tegmentum experiments, and by Ms. Jeanne Chou and Ms. Reena Lawande in conducting the histological analyses. L-364,718 and L-365,260 were kindly supplied by Dr. Roger Freidinger, Merck Sharp and Dohme Research Laboratories, West Point, PA. CI988 was kindly contributed by Dr. Ronald Martin, Parke-Davis Warner-Lambert, Ann Arbor, MI. Ms. Melanie Robinson provided excellent secretarial assistance in the preparation of this manuscript.

Correspondence should be addressed to Dr. Jacqueline N. Crawley, Chief, Unit on Behavioral Neuropharmacology, Experimental Therapeutics Branch, National Institute of Mental Health, Building 10 Room 4N214, Bethesda, MD 20842.

Copyright (C) 1992 Society for Neuroscience 0270-6474/92/123380-12\$05.00/0 these potent, selective, nonpeptide CCK antagonists, with the doses, vehicles, and routes of administration developed in the present studies, will guide further investigations into the role of endogenous CCK in other facets of mesolimbic function.

Cholecystokinin (CCK) coexists with dopamine (DA) in ventral tegmental neurons, projecting to the medial posterior nucleus accumbens, medial olfactory tubercle, and medial septum in the rat brain (Hökfelt et al., 1980a,b; Fallon et al., 1983). mRNA for CCK is seen in cell bodies of the ventral tegmentum and substantia nigra zona compacta of the rat, cat, monkey, and human (Hökfelt et al., 1985; Ingram et al., 1989; Palacios et al., 1989; Savasta et al., 1989; Seroogy et al., 1989a,b; Burgunder and Young, 1990; Cottingham et al., 1990; Jayaraman et al., 1990; Schalling et al., 1990; Schiffmann and Vanderhaeghen, 1991). Retrograde tracing and lesions studies in the rat indicate that a large proportion of the CCK content of the medial posterior nucleus accumbens derives from mesolimbic projections of ventral tegmental neurons, while CCK in the anterior nucleus accumbens and caudate nucleus derives from cortical cell bodies (Hökfelt et al., 1980b, 1988; Studler et al., 1981; Marley et al., 1982; Meyer et al., 1982; Fallon et al., 1983; Seroogy et al., 1989a; Adams and Fisher, 1990). The CCK-DA coexistence in rat brain therefore provides an excellent model system for investigating the functional interactions between coexisting neurotransmitters, with the mesolimbic projection from the ventral tegmental cell bodies to the medial posterior nucleus accumbens being the pathway of the CCK-DA coexistence, while the midbrain dopaminergic projections to the anterior nucleus accumbens and caudate nucleus are non-CCK-containing control pathways.

Interactions between $\mathrm{CCK}$ and DA have been investigated using immunocytochemical, mRNA, biochemical, receptor binding, second messenger, release, neurophysiological, and behavioral techniques (Crawley, 1991). Differential actions of CCK have been reported at the ventral tegmental soma, the posterior nucleus accumbens, and the anterior nucleus accumbens. At the cell body, CCK is excitatory alone, while potentiating the inhibitory actions of DA and the dopaminergic agonist apomorphine (Skirboll et al., 1981; Hommer et al., 1985; Brodie and Dunwiddie, 1987; Freeman and Bunney, 1987; Freeman and Chiodo, 1988; Stittsworth and Mueller, 1990; Zhang et al., 1991). In the nucleus accumbens, CCK blocks the inhibitory effects of DA (White and Wang, 1984; Yim and Mogenson, 1991). Release studies in slice preparations suggest that $\mathrm{CCK}$ potentiates the release of DA in the posterior nucleus accumbens, while 
CCK inhibits the release of DA in the anterior nucleus accumbens (Altar et al., 1988; Marshall et al., 1991). Behavioral studies similarly indicate that CCK potentiates DA-mediated hyperlocomotion and self-stimulation in the posterior nucleus accumbens, while inhibiting DA-mediated behaviors in the anterior nucleus accumbens (Crawley et al., 1985b; De Witte et al., 1987; Weiss et al., 1988; Dauge et al., 1989; Vaccarino and Rankin, 1989; Vaccarino and Vaccarino, 1989). In addition, CCK potentiates DA-mediated hypolocomotion in the ventral tegmental area (Crawley, 1989b).

Two subtypes of CCK receptors have been described (Moran et al., 1986). The peripheral-type or CCK-A receptor is found in the pancreas, gall bladder, vagus nerve, and some brain regions including the nucleus tractus solitarius, area postrema, interpeduncular nucleus, and posterior nucleus accumbens (Moran et al., 1986; Hill et al., 1987, 1990; Rovati and Makovec, 1988; Barrett et al., 1989). Agonist binding at the CCK-A receptor follows the potency profile sulfated CCK octapeptide $\gg$ unsulfated CCK octapeptide > CCK tetrapeptide, and is blocked by the selective, high-affinity compound L-364,718 (Chang and Lotti, 1986). The central-type or CCK-B receptor is found throughout the CNS (Moran et al., 1986; Peleprat et al., 1987; Hill et al., 1990). Agonist binding at the CCK-B receptor follows the profile sulfated $C C K$ octapeptide $\geq$ unsulfated CCK octapeptide $\geq$ CCK tetrapeptide, and is blocked by the selective, high-affinity compounds L-365,260 and CI-988 (Lotti and Chang, 1989; Hughes et al., 1990).

Differential agonist effects of CCK fragments and analogs have been reported, with a $\mathrm{CCK}-\mathrm{A}$ receptor subtype pharmacology indicated in the medial posterior nucleus accumbens, as compared to a CCK-B receptor subtype pharmacology indicated in the anterior nucleus accumbens and ventral tegmental area (Crawley et al., 1986; Vickroy et al., 1988; Altar and Boyar, 1989; Crawley, 1989b; Dauge et al., 1990; Marshall et al., 1991). The present studies were designed to utilize the recently developed, highly selective antagonists of the CCK-A and CCK-B receptor subtypes, to determine definitively the receptor subtype(s) mediating the modulatory actions of CCK on DA-induced exploratory activity. In addition, issues of dose, vehicle, time course, route of administration, and optimal behavioral paradigms are addressed, as the present studies represent the first use of these new CCK antagonists for intracerebral microinjection into the mesolimbic pathway in awake, behaving rats.

The role of endogenous CCK in dopaminergic pathways can effectively be tested with the selective, high-affinity CCK receptor antagonists. The present studies quantitated the contribution of endogenous CCK to exploratory behaviors, by administering CCK-A or CCK-B antagonists alone, or in combination with DA, into the medial posterior nucleus accumbens, the anterior nucleus accumbens, and the ventral tegmental area. In addition, dark-induced hyperlocomotion, a behavioral paradigm designed to mimic DA-induced hyperlocomotion nonpharmacologically, was employed in the present studies of CCK antagonists, to evaluate the contribution of mesolimbic CCK to darkinduced hyperlocomotion. The dark-induced hyperlocomotion paradigm was previously reported to be sensitive to medial posterior nucleus accumbens microinjections of the nonselective CCK antagonist proglumide (Crawley, 1988). In the experiments reported herein, dark-induced hyperlocomotion was quantitated after treatments with CCK-A and CCK-B antagonists, administered intraperitoneally, or microinjected into the medial posterior nucleus accumbens, anterior nucleus accumbens, or ventral tegmental area.

\section{Materials and Methods}

Male Sprague-Dawley rats, $250 \mathrm{gm}$ starting weight, were anesthetized with chloral hydrate and prepared for stereotaxic surgery in accordance with the NIH Guide for the Care and Use of Laboratory Animals. Sterile hypodermic stainless steel guide cannulas ( 24 gauge) were implanted bilaterally into the medial posterior nucleus accumbens, the anterior nucleus accumbens, or the ventral tegmental area, according to the atlas of Paxinos and Watson (1986), as previously described (Crawley et al., 1985a,b; Crawley, 1989b). Coordinates were (1) posterior nucleus accumbens: $1.2 \mathrm{~mm}$ rostral to bregma, $\pm 1.2 \mathrm{~mm}$ lateral to the midline, and $6.0 \mathrm{~mm}$ ventral to the skull; (2) anterior nucleus accumbens: 2.5 $\mathrm{mm}$ rostral to bregma, $\pm 1.2 \mathrm{~mm}$ lateral to the midline, $6.5 \mathrm{~mm}$ ventral to the surface of the skull; and (3) ventral tegmental area: $5.8 \mathrm{~mm}$ caudal to bregma, $\pm 0.5 \mathrm{~mm}$ lateral to the midline, $6.5 \mathrm{~mm}$ ventral to the surface of the skull. A stylet prepared from 31 gauge tubing was inserted flush with the ventral surface of each cannula, to seal the indwelling guide cannula.

After surgery, rats were housed in individual cages within a laminar flow rack, in a temperature- and humidity-controlled vivarium, on a 7 A.M. to 7 P.M. light schedule, with food and water available ad libitum. Behavioral experiments were begun at least 1 week after surgery. Each animal was used twice, with at least 1 week between uses, and with different treatments on each use. At least eight animals were tested per treatment group. At the end of each experiment, animals were killed and their brains stored in formalin for sectioning, thionin staining, and identification of the track locations by light microscopy.

Microinjections were performed with a 31 gauge injection tube, extending $2 \mathrm{~mm}$ below the ventral tip of the guide cannula for the anterior and posterior nucleus accumbens, and $3 \mathrm{~mm}$ below the ventral tip of the guide cannula for the ventral tegmental area. A volume of $0.2 \mu \mathrm{l}$ per injection site was administered over a $1 \mathrm{~min}$ period, using a Sage microinfusion pump (Orion Instruments, Cambridge, $M \Lambda$ ), with the injection tube remaining in place for an additional $30 \mathrm{sec}$, before removal of the injection tube and replacement of the stylet. Antagonists or vehicle were administered $5 \mathrm{~min}$ before saline, DA, or DA+CCK. Physiological saline $(0.9 \%)$ was obtained from the NIH Media Supply. Dopamine, $20 \mu \mathrm{g}$ for the anterior and posterior nucleus accumbens and $3 \mu \mathrm{g}$ for the ventral tegmental area, prepared in saline vehicle, was obtained from Sigma Chemical Company, St. Louis, MO. Cholecystokinin octapeptide sulfate, $10 \mathrm{ng}$ for the anterior and posterior nucleus accumbens and $100 \mu \mathrm{g}$ for the ventral tegmental area, prepared with dopamine in saline vehicle, was obtained from Bachem Bioscience, Inc., Philadelphia, PA. Saline, DA, and DA + CCK solutions were prepared fresh on the day of the experiment and kept refrigerated throughout the day. CI-988, $20 \mathrm{ng}$ or $2 \mu \mathrm{g}$, prepared fresh in saline vehicle on the day of the experiment, was kindly provided by the Parke-Davis Pharmaceuticals Research Division, Warner-Lambert Company, Ann Arbor, MI. The doses chosen were extrapolated from previous receptor binding studies and behavioral studies using systemically administered CI-988 (Hughes et al., 1990). L-364,718 and L-365,260, $10 \mathrm{ng}$ each, prepared primarily in a vehicle of $2.5 \%$ propylene glycol, $2.5 \%$ ethanol, and $95 \%$ warm saline, were kindly provided by the Merck Sharp and Dohme Research Laboratories, Merck and Company, West Point, PA. The vehicle was chosen for its effectiveness in maintaining benzodiazepines in solution (Crawley and Davis, 1982) and effectiveness in maintaining L-364,718 and L-365,260 in solution (C. Dourish, personal communication). The doses chosen were extrapolated from previous receptor binding studies and behavioral studies using systemically administered L-364,718 and L-365,260 (Chang and Lotti, 1986; Khosla and Crawley, 1988; Dourish et al., 1989; Lotti and Chang, 1989). The highest concentration of L-364,718 and of L-365,260 that could be maintained as a warm solution was $10 \mathrm{ng} / 0.2 \mu \mathrm{l}$.

One minute after the last of the four microinjections, the rat was placed in a Digiscan Animal Activity Meter (Omnitech Instruments, Columbus, $\mathrm{OH}$ ) for a $15 \mathrm{~min}$ test session. This paradigm was designed to quantitate the rat's initial exploration of a novel environment. Ambulatory activity was chosen as the automated Digiscan parameter that most accurately reflected exploratory locomotion. Each animal was used twice, with different treatments on the two uses, and at least 1 week between treatment uses. Six to 10 animals were used for each dose of each treatment in each condition. Ambulatory activity data for each 
treatment group were analyzed for significant treatment effects by oneway analysis of variance, followed by a Newman-Keuls test for significance of comparisons between individual means.

Dark-induced hyperlocomotion experiments were conducted as previously described (Crawley, 1988). Rats were cannulated as described above, for microinjections at least 1 week later, into the medial posterior nucleus accumbens, the anterior nucleus accumbens, or the ventral tegmental area. The three CCK antagonists were prepared at the doses described above, in the vehicles described above, for microinjection as described above. In addition, CI-988, L-364,718, and L-365,260 were prepared for intraperitoneal administration over a wide dose range in a volume of $1 \mathrm{ml} / \mathrm{kg}$. The vehicle for CI-988 was $0.9 \%$ physiological saline. Several vehicles were tried for L-364,718 and L-365,260. Comparison of the $2.5 \%$ propylene glycol, $2.5 \%$ ethanol, $95 \%$ warm saline vehicle with the $0.5 \%$ carboxymethylcellulose vehicle (Dourish et al., 1989) indicated some inhibitory behavioral activity for the carboxymethylcellulose vehicle; therefore, the ethanol/propylene glycol/saline vehicle was used for subsequent experiments with L-364,718 and L365,260 . The highest concentration of L-364,718 and L-365,260 that could be maintained in solution with this vehicle was $100 \mu \mathrm{g} / \mathrm{kg} / \mathrm{ml}$. The dose of $1 \mathrm{mg} / \mathrm{kg} \mathrm{L-364,718}$ and L-365,260 was therefore prepared as a sonicated suspension in the $0.5 \%$ carboxymethylcellulose vehicle. Immediately after the intracerebral microinjection, or $30 \mathrm{~min}$ after intraperitoneal injection of vehicle or CCK antagonist, the rat was placed in a Digiscan Animal Activity Meter linked to an Omnitech Analyzer. The Digiscan open field was housed within an environmental chamber with the lights on for half of the animals ("light" condition) and the lights off for half of the animals ("dark" condition). No data were collected during the first $5 \mathrm{~min}$ after the animal was placed in the Digiscan, to allow for recovery from any stress of the injection procedure. Data were collected during the next $30 \mathrm{~min}$, in $10 \mathrm{~min}$ intervals. Horizontal activity was chosen as the automated parameter that most accurately reflected exploratory locomotion in the Omnitech Analyzer data array. The Digiscan system employed in the light-controlled chamber was linked to a Digiscan computer analyzer that yielded several behavioral parameters. The ambulatory activity parameter shown in the experiments of Figures $1-4$, which employed an older, non-computer-linked Digiscan system, was not obtainable in the computer-linked Digiscan system used for the dark-induced hyperlocomotion experiments of Figures 5-12. Histological analysis was performed as described above. Each animal was used twice, with different treatments on the two uses, and at least 1 week between treatment uses. Six to 10 animals were used for each dose of each treatment in each condition. Horizontal activity data for each treatment group were analyzed for significant treatment effects by one-way analysis of variance, followed by a Newman-Keuls test for significance of comparisons between individual means. Comparisons of horizontal activity in the dark versus the light environment, after treatment with different vehicles or no injection, were performed with paired Student's $t$ test.

\section{Results}

Figure 1 illustrates cannula placements in the medial posterior nucleus accumbens, the anterior nucleus accumbens, and the ventral tegmental area. Placements in the medial posterior nucleus accumbens resided in the anatomical subdivision representing the terminal field of the CCK-DA coexistence from the midbrain DA neurons, as described by Hökfelt et al. (1980a,b), and analogous to the subdivision designated as the shell of the accumbens (Heimer et al., 1991; Deutch and Cameron, 1992). Placements in the anterior nucleus accumbens were at least 1.5 $\mathrm{mm}$ farther rostral, at $2.4-2.8 \mathrm{~mm}$ rostral to bregma, where the corpus callosum and caudate nucleus first appear. Approximately $7 \%$ of the animals cannulated in the two accumbens sites showed incorrect placements; behavioral data from these animals were removed from the statistical analyses. Placements in the ventral tegmental area were consistently localized in the central or caudal levels of the ventral tegmentum. Approximately $9 \%$ of the animals cannulated in the ventral tegmental area showed incorrect placements; behavioral data from these animals were removed from the statistical analyses.
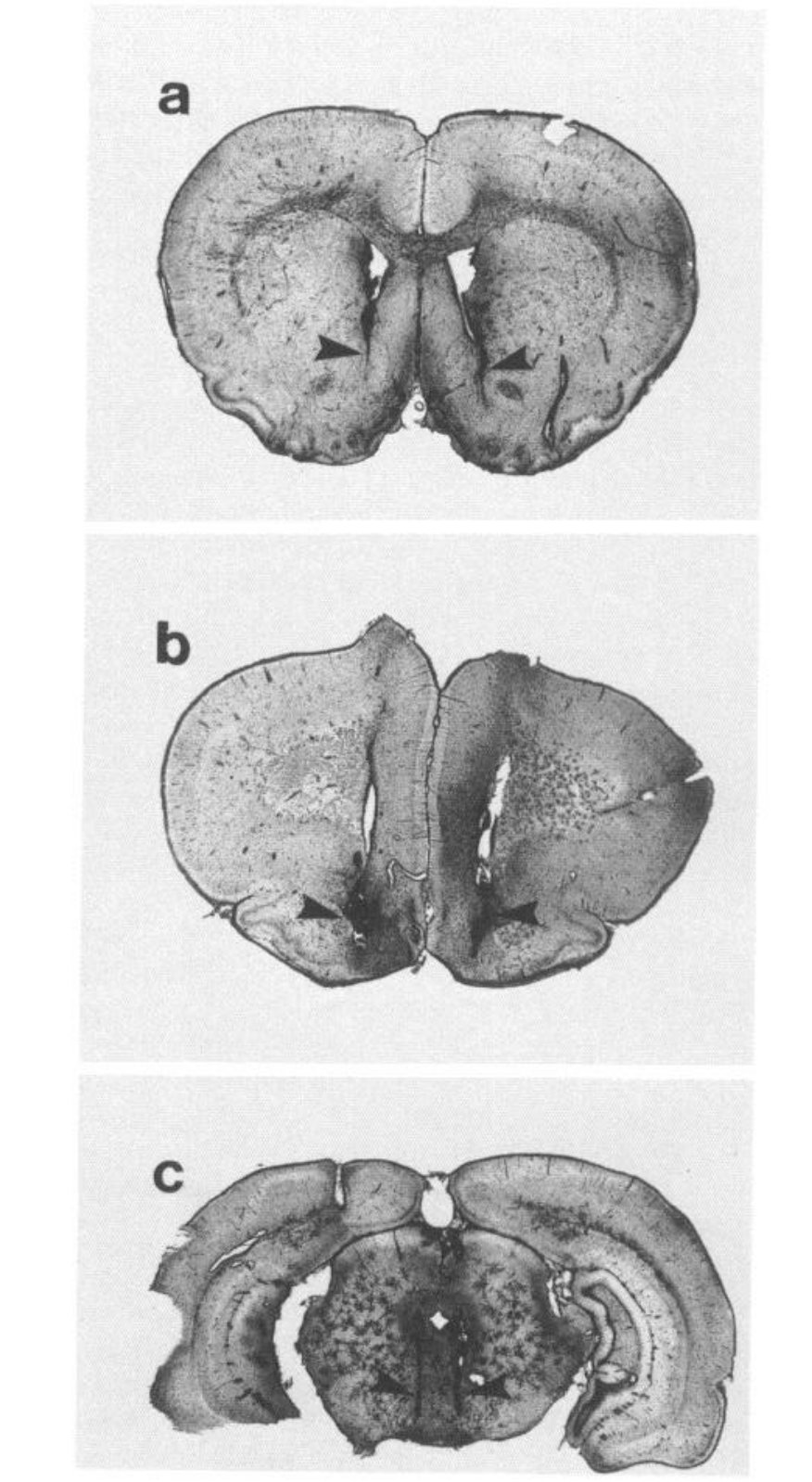

Figure 1. Photomicrographs of bilateral cannula placements in male Sprague-Dawley rat brain: $a$, medial posterior nucleus accumbens; $b$, anterior nucleus accumbens; $c$, ventral tegmental area. Arrowheads indicate the ventral portions of the cannula tracks.

Figure 2 shows the results of experiments with CCK antagonists given $5 \mathrm{~min}$ before saline, $\mathrm{DA}$, or $\mathrm{DA}+\mathrm{CCK}$, at the medial posterior nucleus accumbens site. At this site, DA induced hyperlocomotion, and CCK potentiated DA-induced hyperlocomotion (ANOVA, $F_{2,27}=36.1, p \ll 0.01$; NewmanKeuls, $p<0.01$ for vehicle + saline vs vehicle + DA, $p<0.01$ for vehicle $+\mathrm{DA}$ vs vehicle $+\mathrm{DA}+\mathrm{CCK})$. Pretreatment with L-364,718 (10 ng) antagonized CCK potentiation of DA-induced hyperlocomotion, but had no significant effect on DAinduced hyperlocomotion or on baseline locomotion after saline treatment. However, pretreatment with L-365,260 (10 ng) or with CI-988 (20 ng) had no significant effect on locomotion in the saline, DA, or DA + CCK treatments [pretreatments + saline: ANOVA, $F_{3,26}=0.83$, not significant (NS); Newman-Keuls, 

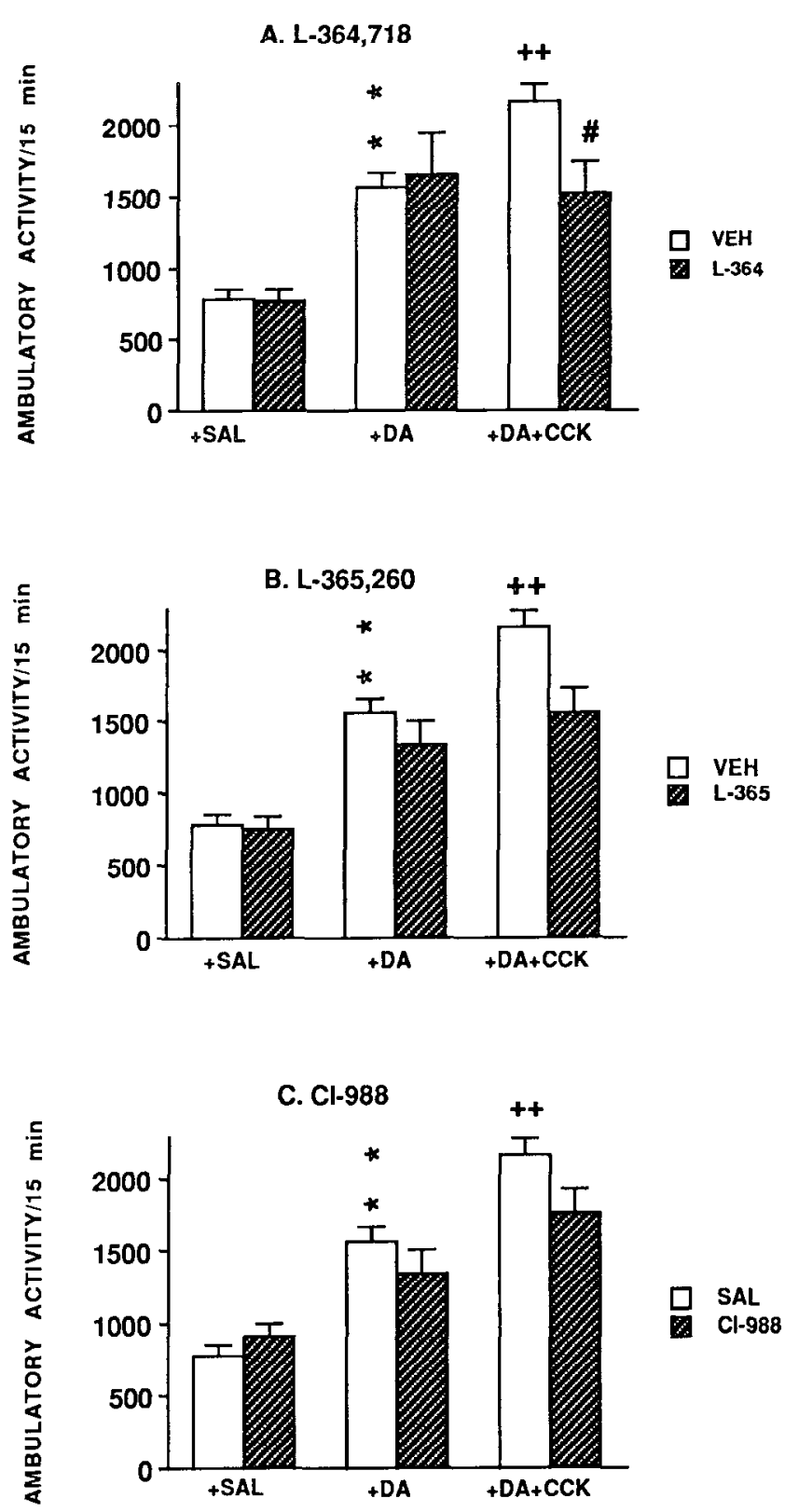

Figure 2. Medial posterior nucleus accumbens. L-364,718 (10 ng), L365,260 (10 ng), CI-988 (20 ng), or vehicle (VEH) was bilaterally microinjected, 5 min before saline $(S A L)$, DA $(20 \mu \mathrm{g})$, or DA $(20 \mu \mathrm{g})+$ CCK octapeptide sulfate $(10 \mathrm{ng})$. Ambulatory locomotor activity was measured in a $15 \mathrm{~min}$ session in a Digiscan animal activity monitor, beginning $1 \mathrm{~min}$ after the last microinjection. In the medial posterior nucleus accumbens, DA increased ambulatory activity, and CCK potentiated DA-induced hyperlocomotion $\left({ }^{* *}, p<0.01\right.$ as compared to vehicle + saline;,$++ p<0.01$ as compared to vehicle + DA). L364,718 significantly antagonized CCK potentiation of DA-induced hyperlocomotion (\#, $p<0.01$ as compared to vehicle + DA+CCK). A suggested trend for L-365,260 and CI-988 to block the CCK potentiation of DA-induced hyperlocomotion in a similar manner was not significant. None of the compounds significantly affected DA-induced hyperlocomotion, or baseline $(S A L)$ ambulatory activity. In Figures 2-12, data are expressed as mean $+\mathrm{SEM}, N=5-10$ per treatment group.

comparisons NS for vehicle + saline vs L-364,718 + saline vs L-365,260 + saline vs CI-988 + saline; pretreatments + DA: ANOVA, $F_{3,26}=1.00$, NS; Newman-Keuls, comparisons NS for vehicle + DA vs L-364,718 + DA vs L-365,260 + DA vs CI-988 + DA; pretreatments + DA+CCK: ANOVA, $F_{3,40}=$

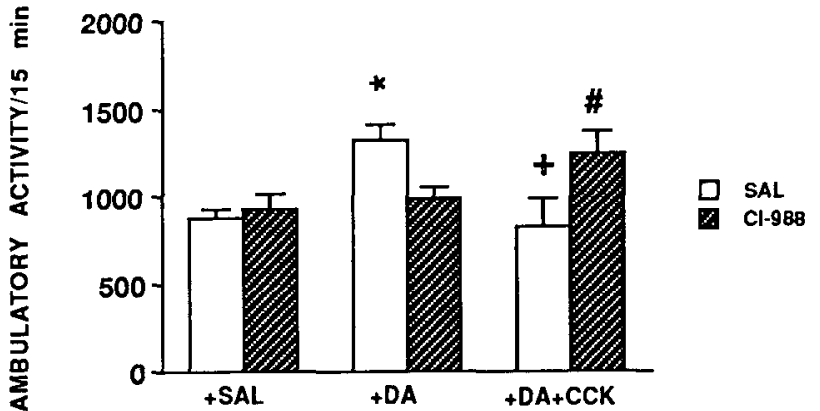

Figure 3. Anterior nucleus accumbens. Cl-988 (20 ng) or saline $(S A L)$ vehicle was microinjected $5 \mathrm{~min}$ before saline, DA $(20 \mu \mathrm{g})$, or DA + CCK octapeptide sulfate $(10 \mathrm{ng})$. At this site, DA increased ambulatory locomotor activity $\left({ }^{*}, p<0.05\right.$ as compared to saline + saline), and CCK inhibited DA-induced hyperlocomotion $(+, p<0.05$ as compared to saline + DA). C.I-988 significantly antagonized CCK inhibition of DA-induced hyperlocomotion (\#, $p<0.05$ as compared to saline + DA+CCK). CI-988 had no significant effect on DA-induced hyperlocomotion, or on baseline $\left(S_{L} 1 L\right)$ ambulatory activity.

$3.41, p<0.05$; Newman-Keuls, comparisons NS for vehicle + $\mathrm{DA}+\mathrm{CCK}$ vs $\mathrm{L}-365,260+\mathrm{DA}+\mathrm{CCK}$ and CI-988 + DA + CCK, $p<0.05$ for vehicle $+\mathrm{DA}+\mathrm{CCK}$ vs L-364,718 + DA + CCK].

Figure 3 shows the results of experiments with CI-988 or saline pretreatment 5 min before saline, DA, or DA $+C C K$ into the anterior nucleus accumbens. At the anterior accumbens site, DA induced hyperlocomotion and CCK antagonized DA-induced hyperlocomotion (ANOVA, $F_{s, 51}=2.77, p<0.05$; Newman-Keuls, $p<0.05$ for saline + saline vs saline $+\mathrm{DA}, p<$ 0.05 for saline $+\mathrm{DA}$ vs saline $+\mathrm{DA}+\mathrm{CCK})$. Pretreatment with CI-988 (20 ng) significantly antagonized CCK-induced attenuation of DA-induced hyperlocomotion but had no significant effect on DA-induced hyperlocomotion or baseline saline locomotion (ANOVA as above, $F_{5,51}=2.77, p<0.05$; NewmanKeuls, NS for comparison of saline + saline vs CI-988 + saline, $\mathrm{NS}$ for comparison of saline $+\mathrm{DA}$ vs CI-988 $+\mathrm{DA}, p<0.05$ for comparison of saline $+\mathrm{DA}+\mathrm{CCK}$ vs CI $-988+\mathrm{DA}+\mathrm{CCK})$.

Figure 4 shows the results of experiments with CCK antagonists given $5 \mathrm{~min}$ before saline, $\mathrm{DA}$, or $\mathrm{DA}+\mathrm{CCK}$, into the ventral tegmental area. At this site, DA induced hypolocomotion, and CCK potentiated DA-induced hypolocomotion (ANOVA, $F_{2.40}=26.1, p \ll 0.01$; Newman-Keuls, $\mathrm{p}<0.01$ for comparison of vehicle + saline vs vehicle $+\mathrm{DA} ; p<0.05$ for comparison of vehicle $+\mathrm{DA}$ vs vehicle $+\mathrm{DA}+\mathrm{CCK})$. $\mathrm{L}$ $364,718(10 \mathrm{ng})$ and L-365,260 (10 ng) had no significant effect on baseline locomotion as compared to vehicle + saline (ANOVA, $F_{2,23}=3.30$, NS). L-364,718 and L-365,260 had no significant effect on DA-induced hypolocomotion as compared to vehicle + DA (ANOVA, $F_{2,27}=0.68$, NS). L-365,260 significantly antagonized CCK potentiation of DA-induced hypolocomotion, while L-364,718 did not (ANOVA, $F_{7.84}, p<0.01$; Newman-Keuls, $p<0.01$ for comparison of vehicle $+\mathrm{DA}+\mathrm{CCK}$ vs $\mathrm{L}-365,260+\mathrm{DA}+\mathrm{CCK}$, NS for comparison of vehicle + $\mathrm{DA}+\mathrm{CCK}$ vs $\mathrm{L}-364,718+\mathrm{DA}+\mathrm{CCK})$. CI-988 (20 ng or $2 \mu \mathrm{g}$ ) had no significant effect on baseline saline locomotion as compared to saline + saline treatment (ANOVA, $F_{2,9}=3.52, \mathrm{NS}$ ). CI-988 had no significant effect on DA-induced hypolocomotion as compared to saline + DA (ANOVA, $F_{2,21}=0.11$, NS). CI-988 significantly antagonized CCK potentiation of DA-induced hypolocomotion, at both doses, $20 \mathrm{ng}$ and $2 \mu \mathrm{g}$, as compared to saline + DA + CCK (ANOVA, $F_{2,24}=3.95, p<0.05$; 

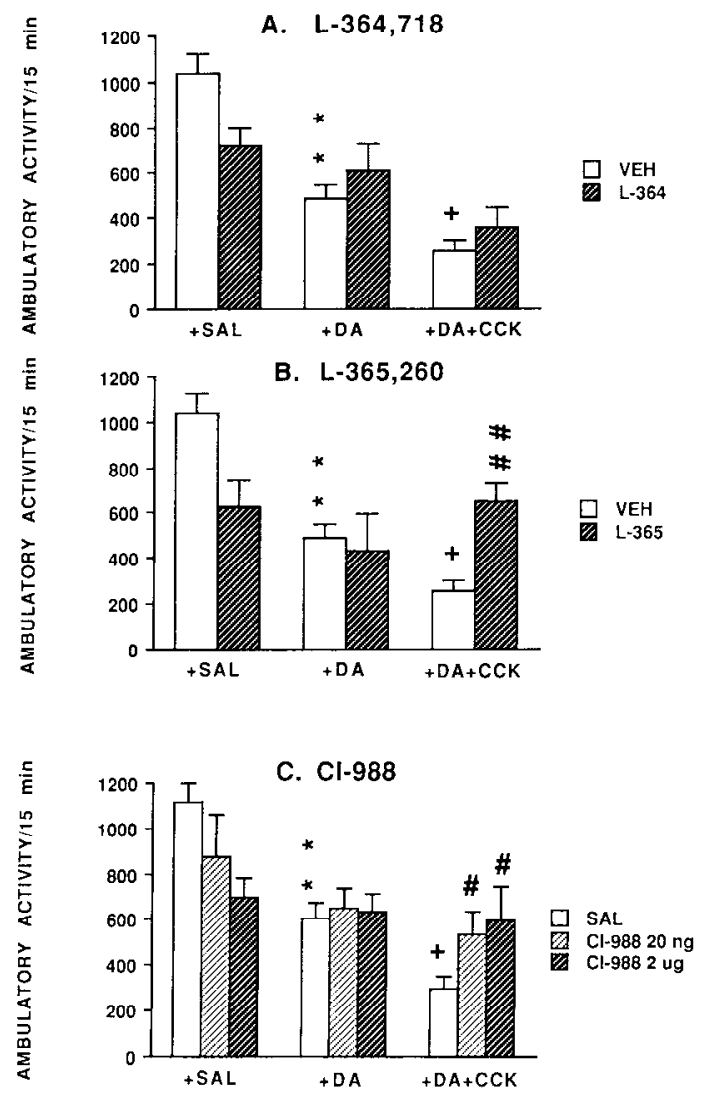

Figure 4. Ventral tegmental area. L-364,718 (10 ng), L-365,260 (10 $\mathrm{ng}$ ), CI-988 (20 ng or $2 \mu \mathrm{g}$ ), or vehicle ( $V E H$ ) was microinjected $5 \mathrm{~min}$ before saline $(S A L), \mathrm{DA}(3 \mu \mathrm{g})$, or DA + CCK octapeptide sulfate (100 $\mu \mathrm{g})$. At this site, DA inhibited exploratory locomotion $\left({ }^{* *}, p<0.01\right.$ as compared to vchicle 1 saline), and CCK potentiated D $\Lambda$-induced hypolocomotion $(+, p<0.05$ as compared to vehicle $+\mathrm{DA})$. At this site, L-365,260 and CI-988 significantly antagonized CCK potentiation of DA-induced hypolocomotion, whereas $\mathrm{L}-364,718$ did not (\#, $p<0.05$; \#\#, $p<0.01$; as compared to vehicle + DA+CCK). L-365,260, CI988, and L-364,718 did not significantly affect DA-induced hypolocomotion, or baseline $(S A L)$ ambulatory activity, although a trend for inhibition of baseline activity was observed for the antagonists.

Newman-Keuls, $p<0.05$ for saline + DA + CCK vs 20 ng CI$988+\mathrm{DA}+\mathrm{CCK}, p<0.05$ for saline $+\mathrm{DA}+\mathrm{CCK}$ vs $2 \mu \mathrm{g} \mathrm{CI}-$ $988+\mathrm{DA}+\mathrm{CCK})$.

Figure 5 characterizes the dark-induced hyperlocomotion paradigm for exploratory locomotion and habituation to the novelty of the Digiscan open ficld environment. Horizontal activity was measured in 10 min time blocks over the 30 min test session. Horizontal activity declined over the three consecutive $10 \mathrm{~min}$ blocks in both the light and dark conditions. Horizontal activity was significantly higher for the dark condition than the light condition in the first 10 min block only (ANOVA, $F_{5.24}=5.33$, $p<0.01$; Newman-Keuls, $p<0.05$ for light vs dark, $0-10 \mathrm{~min}$ block).

Figure 6 characterizes the dark-induced hyperlocomotion paradigm for uninjected rats and for rats after intraperitoneal, posterior nucleus accumbens, anterior nucleus accumbens, or ventral tegmental area administration of three possible vehicles for the CCK antagonists. The vehicles tested were $0.9 \%$ physiological saline, $0.5 \%$ carboxymethylcellulose (Dourish et al., 1989), and $2.5 \%$ ethanol, $2.5 \%$ propylene glycol, $95 \%$ warm saline (Crawley and Davis, 1982). Horizontal activity was significantly

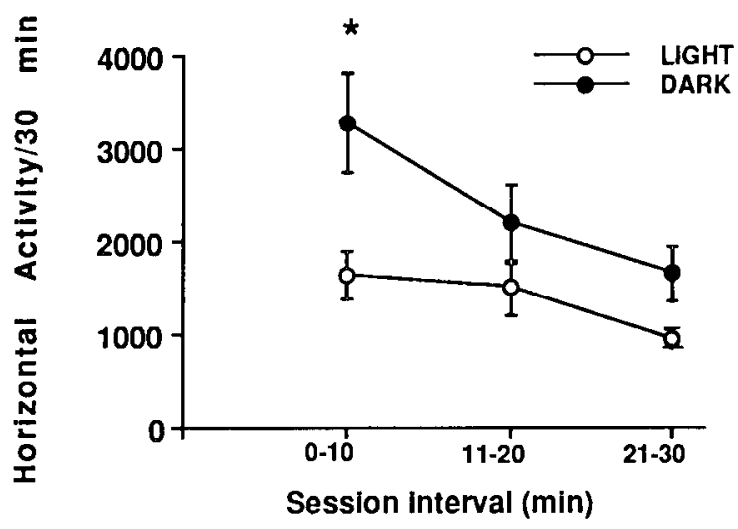

Figure 5. Dark-induced hyperlocomotion paradigm. Horizontal locomotor activity measured cumulatively over a $30 \mathrm{~min}$ test session was higher when the Digiscan open field was housed in a dark environment (Digiscan arena enclosed in a chamber with the chamber lights off) than in a lighted environment (chamber lights on). Data analysis of $10 \mathrm{~min}$ time blocks indicates the largest difference between dark and light activity in the first $10 \mathrm{~min}$ in the open field $\left(^{*}, p<0.05\right.$ dark vs light).

elevated in the dark Digiscan environment as compared to the light Digiscan environment after intraperitoneal saline treatment $(t=2.81$, df $=11, p<0.02)$ and after intraperitoneal ethanol/propylene glycol/saline treatment $(t=3.02$, df $=28, p$ $<0.01$ ). No significant difference between light and dark conditions was measured in horizontal activity scores after treatment with carboxymethylcellulose vehicle $(t=0.99$, df $=21$, NS), reflecting lower scores on horizontal activity in the dark, indicating that this vehicle would not be optimal for experiments with L-364,718 and L-365,260 in the dark-induced hyperlocomotion paradigm. In the medial posterior nucleus accumbens, a significant increase in horizontal activity was detected in the dark as compared to in the light, for no microinjection $(t=3.27$, $\mathrm{df}=12, p<0.01$ ), ethanol/propylene glycol/saline microinjection $(t=3.51, \mathrm{df}=12, p<0.01)$, and saline microinjection $(t$ $=2.32$, $\mathrm{d} \Gamma=8, p<0.05$ ). In the anterior nucleus accumbens, a significant increase in horizontal activity was detected in the dark as compared to in the light, for saline vehicle microinjection $(t=2.34$, $\mathrm{df}=7, p<0.05)$. In the ventral tegmental area, a significant increase in horizontal activity was detected in the dark as compared to in the light, for no microinjection $(t=2.84$, $\mathrm{df}=6, p<0.05)$, ethanol/propylene glycol/saline microinjection $(t=2.49, \mathrm{df}=8, p<0.05)$, and for saline microinjection $(t=$ $2.32, \mathrm{df}=8, p<0.05)$. Based on the results of the experiments of Figure 5, the vehicle chosen for intrapcritoncal and intracerebral studies with L-364,718 and L-365,260 was the $2.5 \%$ ethanol, $2.5 \%$ propylene glycol, $95 \%$ warm saline solution; saline was chosen as the vehicle for experiments with CI-988.

Figure 7 shows the lack of effect of intraperitoneally administered L-364,178 on dark-induced hyperlocomotion. Intraperitoneal doses of $\mathrm{L}-364,718$ from $100 \mathrm{ng} / \mathrm{kg}$ to $1 \mathrm{mg} / \mathrm{kg}$ had no significant effect on horizontal activity in the light condition as compared to vehicle treatment (ANOVA, $F_{5,55}=0.52$, NS) Similarly, L-364,718 had no significant effect on horizontal activity in the dark condition as compared to vehicle treatment (ANOVA, $F_{\text {s.5s }}=2.88, p<0.05$; Newman-Keuls, $p<0.05$ for the comparison of $10 \mu \mathrm{g} / \mathrm{kg}$ vs $1 \mathrm{mg} / \mathrm{kg}$, but no significant differences were detected between vehicle and any dose of L-364,718).

Figure 8 shows the effects of intraperitoneally administered L-365,260 on dark-induced hyperlocomotion. Doses of 

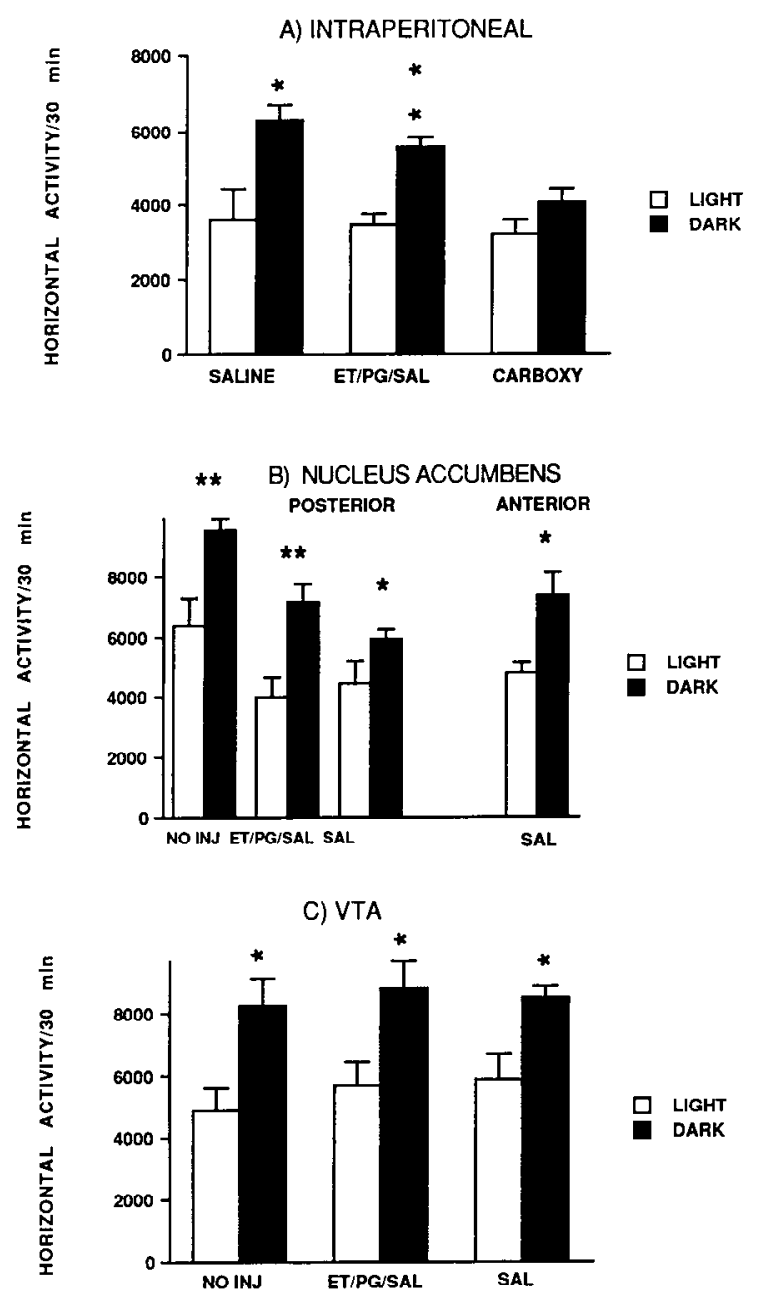

Figure 6. Comparison of vehicle treatments in the dark-induced hyperlocomotion paradigm. Significantly higher cumulative $30 \mathrm{~min}$ horizontal activity was displayed by rats in the dark environment as compared to the light environment after no injection, intraperitoneal treatment with saline, and intraperitoneal treatment with $2.5 \%$ ethanol, $2.5 \%$ propylene glycol, $95 \%$ warm saline $(*, p<0.05 ; * *, p<0.01$; dark vs light), but not after intraperitoneal treatment with $0.5 \%$ carboxymethylcellulose. Dark-induced hyperlocomotion was significant after microinjection of $2.5 \%$ ethanol, $2.5 \%$ propylene glycol, $95 \%$ warm saline, or after $0.9 \%$ physiological saline, into the medial posterior nucleus accumbens, the anterior nucleus accumbens, and the ventral tegmental area (VTA; ${ }^{*}, p<0.05 ;{ }^{* *}, p<0.01$; dark vs light).

$\mathrm{L}-365,260$ from $100 \mathrm{ng} / \mathrm{kg}$ to $1 \mathrm{mg} / \mathrm{kg}$ had no significant effect on horizontal activity in the light condition, as compared to vehicle treatment (ANOVA, $F_{4,57}=0.81$, NS). L-365,260 significantly decreased horizontal activity in the dark condition, as compared to vehicle treatment (ANOVA, $F_{6.53}=7.15, p<$ 0.01 ; Newman-Keuls, $p<0.01$ for the comparison of $1 \mathrm{mg} / \mathrm{kg}$ vs vehicle, $p<0.05$ for the comparison of $10 \mu \mathrm{g} / \mathrm{kg}$ vs vehicle, $p<0.05$ for the comparison of $100 \mathrm{ng} / \mathrm{kg}$ vs vehicle).

Figure 9 shows the effects of intraperitoneally administered CI-988 on dark-induced hyperlocomotion. Doses of CI-988 (10 $\mu \mathrm{g} / \mathrm{kg}$ and $1 \mathrm{mg} / \mathrm{kg}$ ) had no significant effect on horizontal activity in the light condition, as compared to vehicle treatment $\left(\mathbf{F}_{2,32}=0.59, \mathrm{NS}\right)$. CI-988 had no significant effect on horizontal activity in the dark condition, as compared to vehicle treatment $\left(\mathrm{F}_{2,26}=0.10, \mathrm{NS}\right)$.

Figure 10 shows the lack of effects of CCK antagonists on
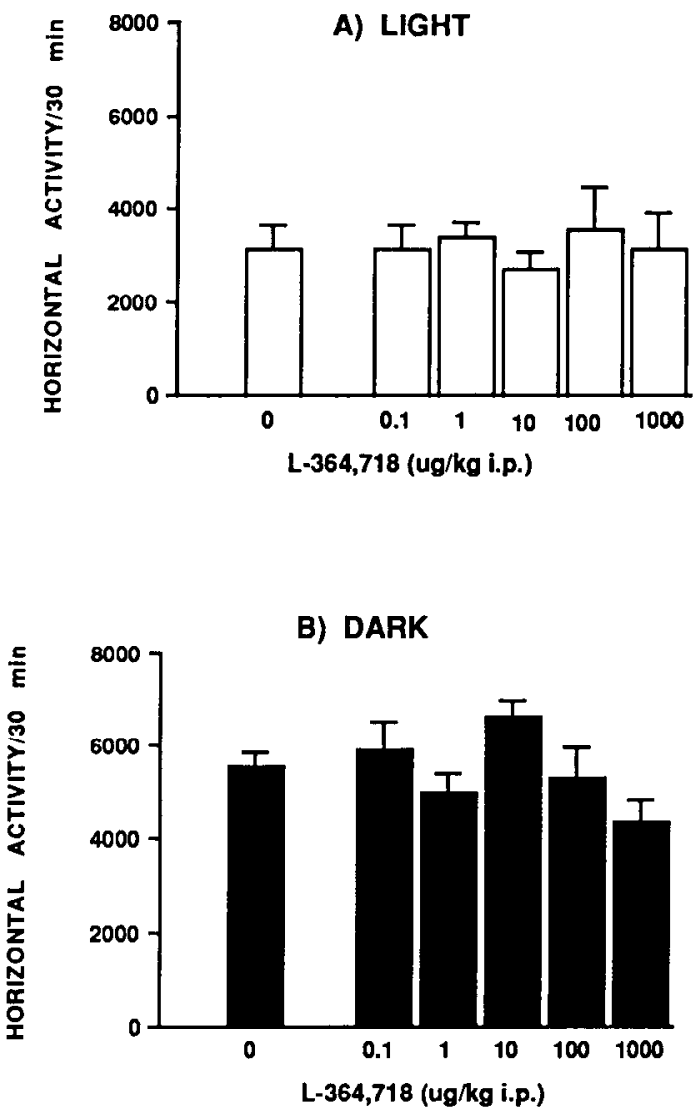

Figure 7. Lack of effects of intraperitoneal L-364,718 on dark-induced hyperlocomotion. Doses of $\mathrm{I}-364,718$ from $100 \mathrm{ng} / \mathrm{kg}$ to $100 \mu \mathrm{g} / \mathrm{kg}$ were administered intraperitoneally in a volume of $1 \mathrm{ml} / \mathrm{kg}$ in the ethanol/propylene glycol/saline vehicle, $35 \mathrm{~min}$ before the start of the 30 min test session. The dose of $1 \mathrm{mg} / \mathrm{kg}$ was prepared in $0.5 \%$ carboxymethylcellulose. L-364,718 had no significant effect on horizontal activity in either the light or the dark environment at any of the doses tested.

dark-induced hyperlocomotion when microinjected into the medial posterior nucleus accumbens. L-364,718 (10 ng), L$365,260(10 \mathrm{ng})$, and CI-988 (20 $\mathrm{ng}$ or $2 \mu \mathrm{g})$ had no significant effect on horizontal activity in the light condition as compared to ethanol/propylene glycol/saline vehicle or as compared to saline vehicle (ANOVA, $F_{5,38}=0.73$, NS). L-364, 718, L-365, 260, and CI-988 had no significant effect on horizontal activity in the dark condition as compared to either vehicle (ANOVA, $F_{5,42}$ $=1.09$, NS).

Figure 11 shows the lack of effects of CI-988 on dark-induced hyperlocomotion when microinjected into the anterior nucleus accumbens. CI-988 (20 ng or $2 \mu \mathrm{g}$ ) had no significant effect on horizontal activity in the light condition as compared to saline vehicle (ANOVA, $F_{2.9}=1.04$, NS). CI-988 $(20 \mathrm{ng}$ or $2 \mu \mathrm{g}$ ) had no significant effect on horizontal activity in the dark condition as compared to saline vehicle (ANOVA, $F_{2,18}=1.30, \mathrm{NS}$ ).

Figure 12 shows the lack of effects of CCK antagonists on dark-induced hyperlocomotion when microinjected into the ventral tegmental area. L-364,718 (10 ng), L-365,260 (10 ng), and CI-988 (20 ng or $2 \mu \mathrm{g}$ ) had no significant effect on horizontal activity in the light condition as compared to ethanol/propylene glycol/saline vehicle or to saline vehicle (ANOVA, $F_{7.39}=0.51$, NS). L-364,7 18, L-365,260, and CI-988 had no significant effect on horizontal activity in the dark condition as compared to either vehicle (ANOVA, $F_{7,41}=1.15, \mathrm{NS}$ ). 

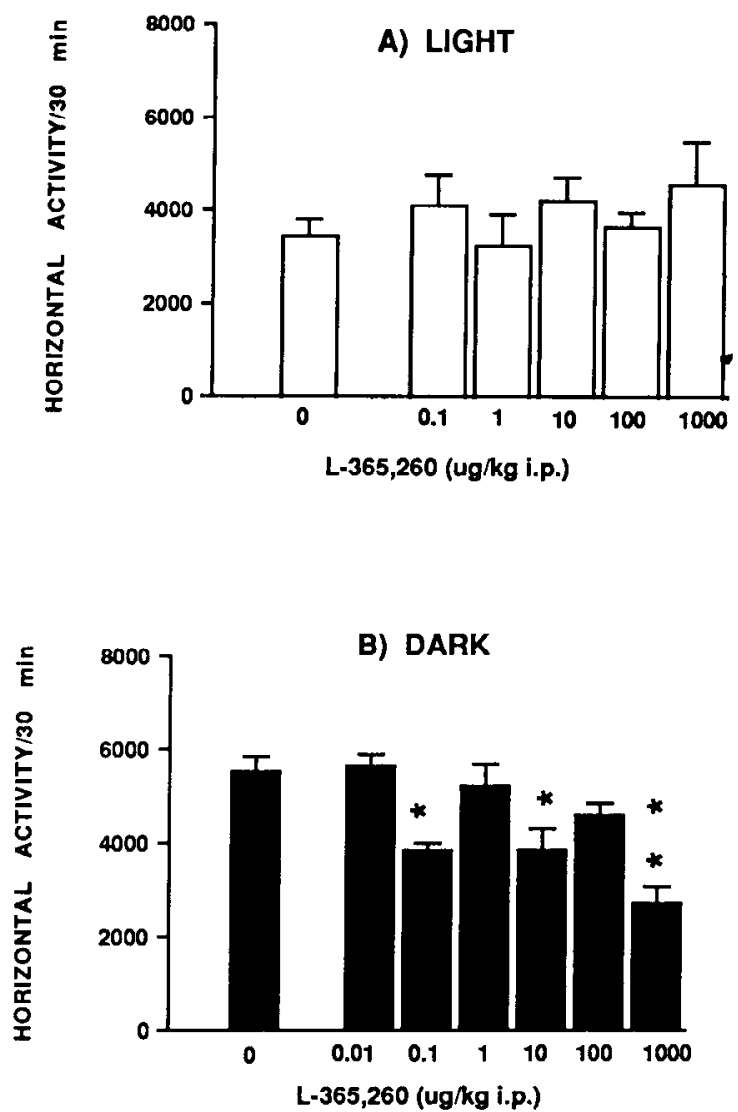

Figure 8. Effects of intraperitoneal L-365,260 on dark-induced hyperlocomotion. Doses of L-365,260 from $10 \mathrm{ng} / \mathrm{kg}$ to $100 \mu \mathrm{g} / \mathrm{kg}$ were administered intraperitoneally in a volume of $1 \mathrm{ml} / \mathrm{kg}$ in the ethanol/ propylene $\mathrm{glycol} / \mathrm{saline}$ vehicle, $35 \mathrm{~min}$ before the $30 \mathrm{~min}$ test session. The dose of $1 \mathrm{mg} / \mathrm{kg}$ was prepared in $0.5 \%$ carboxymethylcellulose. L365,260 had no significant effect on horizontal activity in the light environment at any of the doscs tested. L-365,260 significantly inhibitcd dark-induced hyperlocomotion at doses of $100 \mathrm{ng} / \mathrm{kg}, 10 \mu \mathrm{g} / \mathrm{kg}$, and 1

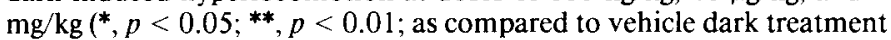
group).

\section{Discussion}

Previous behavioral studies have demonstrated that CCK potentiates DA-induced hyperlocomotion, amphetamine-induced hyperlocomotion, amphetamine-induced stereotypy, and selfstimulation, when microinjected into the medial posterior nucleus accumbens (Crawley et al., 1985a; De Wittc ct al., 1987; Weiss et al., 1988; Vaccarino and Rankin, 1989; Vaccarino and Vaccarino, 1989). A biphasic dose-response curve indicated that picogram to nanogram doses of CCK potentiated DA, while microgram doses had no effect or inhibited DA, in several behavioral paradigms (Widerlov et al., 1983; Crawley et al., 1985a; Britton et al., 1989). Unsulfated cholecystokinin octapeptide and cholecystokinin tetrapeptide were inactive at doses up to 1000 times the active dose of sulfated cholecystokinin octapeptide, indicating a peripheral-type or CCK-A pharmacology (Crawley et al., 1986). The present studies demonstrate that a subtype-selective antagonist of the CCK-A receptor, L-364,718, effectively antagonized the ability of CCK to potentiate DAinduced hyperlocomotion in the medial posterior nucleus accumbens. The present results are consistent with recent studies demonstrating a CCK-A receptor subtype mediating CCK po-
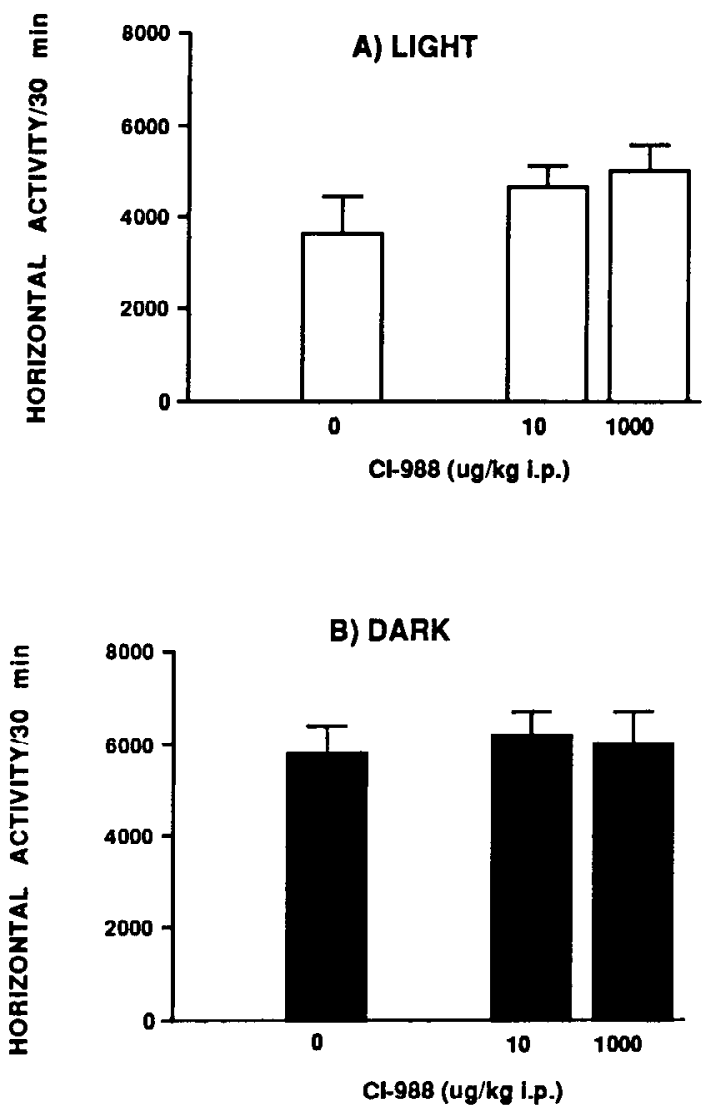

Figure 9. Lack of effects of intraperitoneal CI-988 on dark-induced hyperlocomotion. Doses of CII-988 $(10 \mu \mathrm{g} / \mathrm{kg}$ and $1 \mathrm{mg} / \mathrm{kg})$ were administered intraperitoneally in a volume of $1 \mathrm{ml} / \mathrm{kg}$ in saline vehicle, $35 \mathrm{~min}$ before the $30 \mathrm{~min}$ test session. CI-988 had no significant effect on horizontal activity in either the light or the dark environment at the doses tested.

tentiation of DA release from the posterior nucleus accumbens of the rat in vitro (Vickroy et al., 1988; Marshall et al., 1991). The terminal field of the mesolimbic neurons in which CCK and DA coexist, therefore, appears to utilize a CCK-A mechanism for the actions of CCK in potentiating dopaminergic functions. At variance with this conclusion are neurophysiological studies reporting a CCK-A pharmacology mediating the excitatory effects of CCK in the rat nucleus accumbens, which block the inhibitory effects of dopaminergic agonists in the posterior nucleus accumbens (Wang et al., 1988; Yim and Mogenson, 1991). CCK-A receptors have been reported in the posterior nucleus accumbens of the cow brain (Barrett et al., 1989), and in the nucleus accumbens of cynomolgus monkey brain (Graham et al., 1991). Inferential evidence suggests the presence of CCK-A receptors in the nucleus accumbens of rat brain (Rovati and Makovec, 1988). However, no direct autoradiographic or receptor binding assays have detected measurable concentrations of CCK-A receptors in the rat nucleus accumbens to date.

Behavioral studies in our laboratory previously demonstrated that CCK potentiates DA-induced hypolocomotion in the ventral tegmental area (Crawley, 1989b). Unsulfated CCK octapeptide was active at a dose equimolar to sulfated CCK octapeptide; CCK tetrapeptide was active at a dose just four times greater than the active dose of sulfated CCK octapeptide, and the CCK-B agonist BC 264 was active at this site (Crawley, 1989b; Dauge et al., 1990). In the present studies, the CCK-B 


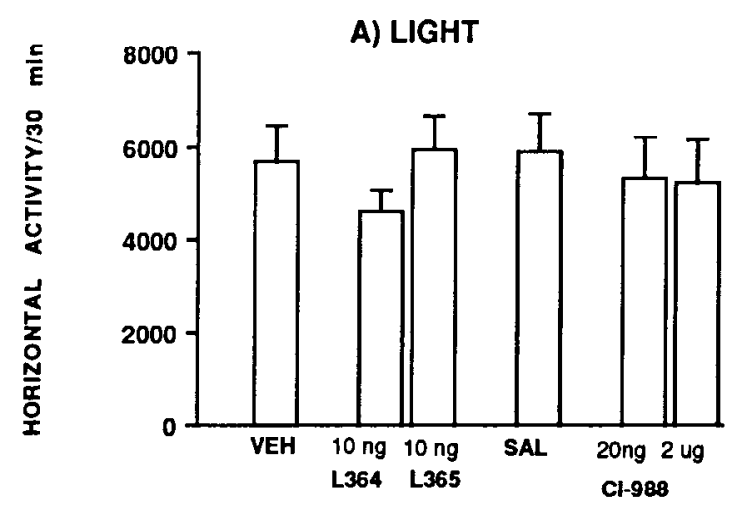

B) DARK

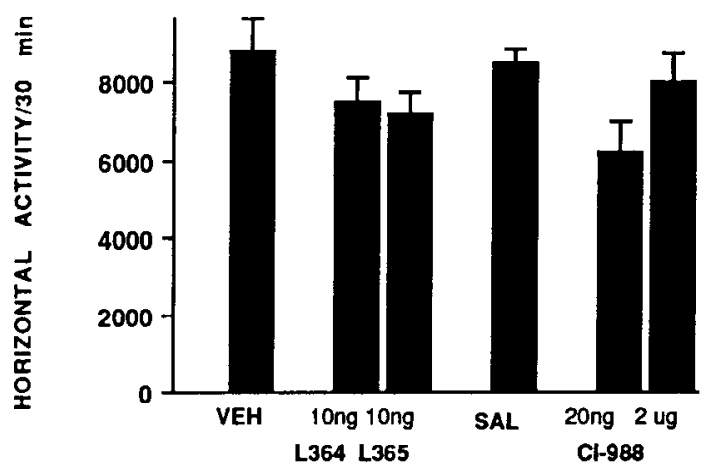

Figure 10. Medial posterior nucleus accumbens, dark-induced hyperlocomotion. L-364,718 (10 ng), L-365,260 (10 ng), CI-988 (20 ng or 2 $\mu \mathrm{g})$, or the appropriate vehicle ( $V E H, S A L$, saline) was microinjected bilaterally into the medial posterior nucleus accumbens in a volume of $0.2 \mu \mathrm{l}$, immediately before placement of the rat in the Digiscan open field in either the light or the dark environment. The CCK antagonists had no significant effect on horizontal activity either in the light or in the dark, at the doses tested.

antagonists L-365,260 and Cl-988 antagonized the potentiating actions of CCK on DA-induced hypolocomotion in the ventral tegmental area. The present behavioral results are consistent with neurophysiological studies showing that unsulfated cholecystokinin octapeptide is approximately as active as sulfated cholecystokinin octapeptide in potentiating apomorphine and DA-induced reductions in neuronal firing in ventral tegmental and substantia nigra neurons (Hommer and Skirboll, 1983; Hommer et al., 1986). The cell bodies of the mesolimbic neurons in which CCK and DA coexist, therefore, appear to utilize a CCK-B mechanism for the actions of CCK in inhibiting dopaminergic functions.

Previous behavioral studies in our laboratory have demonstrated that CCK inhibits or has no effect on DA-induced hyperlocomotion in the anterior nucleus accumbens (Crawley et al., 1985b). Behavioral studies from other laboratories demonstrated that CCK attenuates amphetamine-induced hyperlocomotion and self-stimulation in the anterior nucleus accumbens (Vaccarino and Rankin, 1989; Vaccarino and Vaccarino, 1989). In the present studies, the CCK-B antagonist CI-988 antagonized the ability of CCK to inhibit DA-induced hyperlocomotion in the anterior nucleus accumbens. The present behavioral findings are consistent with in vitro release studies indicating a CCK-B receptor mediating the CCK suppression of DA release in the rostral nucleus accumbens (Altar and Boyar, 1989; Marshall et al., 1991). The terminal field of the mesolim-

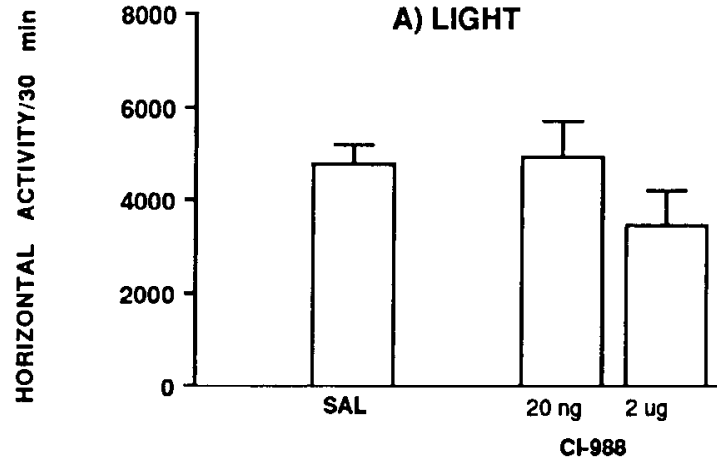

B) DARK

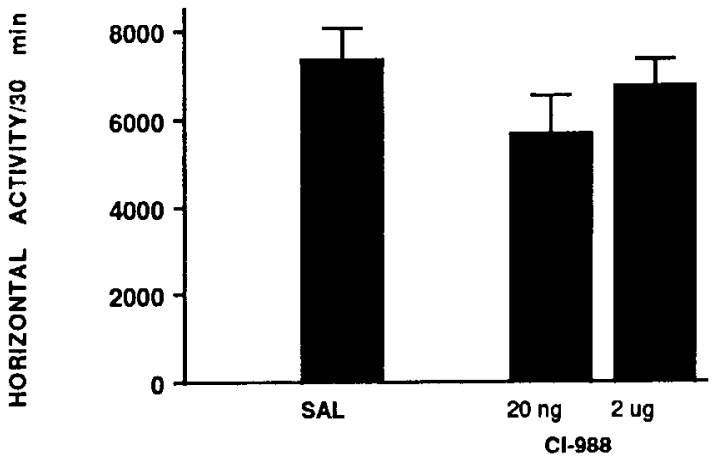

Figure 11. Anterior nucleus accumbens, dark-induced hyperlocomotion. CI-988 (20 ng or $2 \mu \mathrm{g}$ ) or saline vehicle ( $S A L$ ) was microinjected bilaterally into the anterior nucleus accumbens in a volume of $0.2 \mu \mathrm{l}$, immediately before placement of the rat in the Digiscan open field in either the light or the dark. CI-988 had no significant effect on horizontal activity either in the light or in the dark, at the doses tested.

bic neurons in which CCK and DA do not coexist, therefore, appears to utilize a CCK-B mcchanism for the modulatory actions of CCK in inhibiting dopaminergic functions.

The present studies provide the first information on active doses of L-364,718, L-365,260, and CI-988 for microinjection studies in the rat mesolimbic pathway. Several caveats must be considered in interpreting the present data. Solubility limitations are a serious consideration for microinjection studies of CCK antagonists. Given the small volumes used in microinjection studies (e.g., $0.2 \mu \mathrm{l}$ ), compounds need to be prepared in high concentrations (e.g., $1 \mathrm{mg} / \mathrm{ml}$ ) to allow testing of the upper regions of a dose-response curve (e.g., $200 \mathrm{ng} / 0.2 \mu \mathrm{l}$ ). CI-988 is water soluble, such that two divergent doses, $20 \mathrm{ng}$ and $2 \mu \mathrm{g}$, could be tested in the present studies. However, L-364,718 and L-365,260 are not water soluble; therefore, a vehicle must be chosen that dissolves or suspends the compound for accurate dosing, and that itself has minimal biological activity. Concentrated dimethyl sulfoxide and concentrated ethanol are often used as vehicles in biochemical experiments, but may have behavioral effects when microinjected into the brain. Carboxymethylcellulose $(0.5 \%)$, the vehicle used to suspend L-364,718 and L-365,260 for systemic injections (Dourish et al., 1989), is relatively viscous. In the present experiments, the $0.5 \%$ carboxymethylcellulose suspensions with L-364,718 and L-365,260 often clogged the 31 gauge injection tubes used in the present experiments. The warmed solution of $2.5 \%$ ethanol, $2.5 \%$ pro- 
pylene glycol, $95 \%$ saline, used previously in studies of benzodiazepines (Crawley and Davis, 1982), maintained both L364,718 and $\mathrm{L}-365,260$ in solution at doses up to $10 \mathrm{ng} / 0.2 \mu \mathrm{l}$, but higher concentrations did not remain in solution. The present studies therefore do not represent dose-response curves, but employed the highest dose of L-364,718 and of L-365,260 that could be maintained in solution. The dose of $10 \mathrm{ng} / 0.2 \mu \mathrm{l}$ is consistent with extrapolations from the active doses of L-364,7 18 and L-365,260 given systemically (Dourish et al., 1989), given the ability of these compounds to diffuse through tissue rapidly and to cross the blood-brain barrier (Pullen and Hodgson, 1987). However, the lack of effects of $10 \mathrm{ng} / 0.2 \mu \mathrm{l} \mathrm{L-364,718} \mathrm{in} \mathrm{the}$ ventral tegmental area and the anterior nucleus accumbens, and the trend toward but lack of significant effects of $10 \mathrm{ng} / 0.2 \mu \mathrm{l}$ L-365,260 in the medial posterior nucleus accumbens, must be interpreted with caution. It is possible that higher doses of these compounds would inhibit the behavioral actions of CCK. Complete dose-response studies are necessary to evaluate definitively the relative potencies of $\mathrm{CCK}-\mathrm{A}$ versus $\mathrm{CCK}-\mathrm{B}$ antagonists in the medial posterior nucleus accumbens, anterior nucleus accumbens, and ventral tegmental area. Development of more soluble CCK-A antagonists will be required to conduct complete dose-response curves. The data obtained herein on the differential actions of L-364,718 and L-365,260 (10 ng/0.2 $\mu \mathrm{l})$, combined with the differential actions of the water-soluble CCK-B antagonist CI-988 at the three anatomical sites, can be considered as preliminary indications of differential receptor subtype involvement in the behavioral effects of $\mathrm{CCK}$ at these three sites.

At the doses tested, no significant effects of L-364,718, L365,260 , or CI-988 were seen when microinjected $5 \mathrm{~min}$ before saline into the medial posterior nucleus accumbens, anterior nucleus accumbens, or ventral tegmental area. $\Lambda$ trend toward reduction in ambulatory activity was seen for $\mathrm{L}-364,718+$ saline, L-365,260 + saline, and CI-988 + saline, as compared to saline + saline, after microinjections into the ventral tegmental area. These three trends did not reach statistical significance, perhaps due to the larger variance in these treatment groups than in others, and/or the smaller number of animals with correct cannula placements in these groups $(N=5-7)$ as compared to other groups $(N=6-10)$. The possibility that CCK antagonists reduce exploratory activity when microinjected into the ventral tegmental area is not supported by the results of the dark-induced hyperlocomotion experiments discussed below.

At the doses used, no significant effects of L-364,718, L365,260 , or CI-988 were seen when microinjected 5 min before DA, into the medial posterior nucleus accumbens, anterior nucleus accumbens, or ventral tegmental area. There was a trend for CI-988 to reduce DA-induced hyperlocomotion in the anterior nucleus accumbens. This trend did not reach statistical significance using one-way ANOVA with Newman-Keuls comparison of CI-988 + DA versus saline + DA. It may be important to note that the hyperlocomotion induced by DA in the anterior nucleus accumbens was of a somewhat smaller magnitude than the hyperlocomotion induced by DA in the medial posterior nucleus accumbens.

The general lack of effect of these three CCK antagonists on baseline (saline vehicle) exploratory activity, and on DA-induced hyperlocomotion and hypolocomotion, is relevant to the issue of the contribution of endogenous mesolimbic CCK to exploratory activity. A current hypothesis of the functional activity of coexisting neurotransmitters is the frequency coding

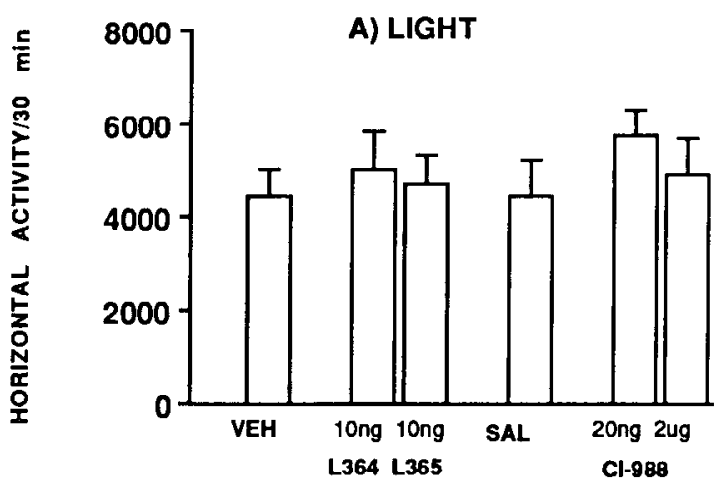

B) DARK

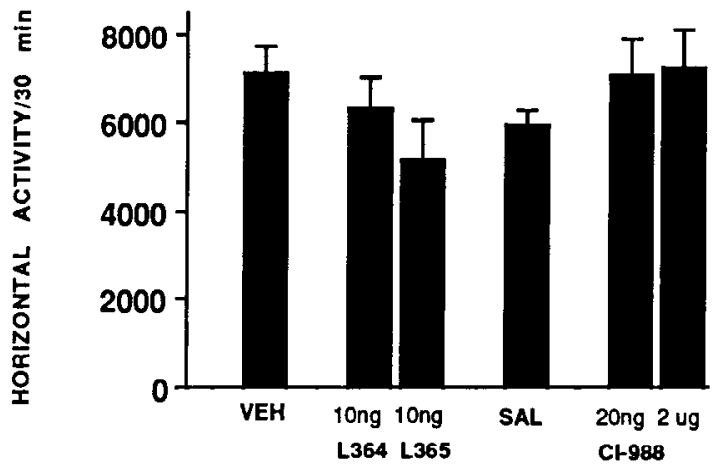

Figure 12. Ventral tegmental area, dark-induced hyperlocomotion. L364,718 (10 ng), L-365,260 (10 ng), Cl-988 (20 ng or $2 \mu \mathrm{g}$ ), or the appropriate vehicle ( $V E H ; S A L$, saline) was microinjected bilaterally into the ventral tegmental area in a volume of $0.2 \mu \mathrm{l}$, immediately before placement of the rat in the Digiscan open field in either the light or the dark. The CCK antagonists had no significant effect on horizontal activity either in the light or in the dark, at the doses tested.

hypothesis (Bartfai et al., 1988). As reported for coexisting peptides and catecholamines in peripheral neurons, the "classical" neurotransmitter is released at low frequencies of electrical or chemical stimulation, while the peptide cotransmitter is released along with the "classical" transmitter at higher frequencies of electrical or chemical stimulation. It is possible that a high frequency of neuronal activity is required for the release of endogenous CCK from terminals of the mesolimbic DA pathway. Microinjection of DA may produce hyperlocomotion by activating postsynaptic receptors in the nucleus accumbens, without activating presynaptic release of endogenous DA and CCK. Treatment with a presynaptic activator such as amphetamine or electrical stimulation of the ventral tegmental area may be more likely to cause presynaptic release of endogenous DA and CCK. A behavioral event must therefore activate mesolimbic neurons up to a sufficiently high rate of firing to release endogenous CCK, before an effect of a CCK antagonist can be detected.

In an attempt to design a behavioral paradigm that would maximally activate mesolimbic neurons, we developed the darkinduced hyperlocomotion paradigm. Horizontal activity of rats in the Digiscan in a dark chamber was at least $50 \%$ higher than horizontal activity of rats in the Digiscan in a light chamber. Other computer-generated Digiscan Analyzer parameters of exploratory activity, including total distance and vertical activity, 
also increased in the dark; however, the horizontal activity parameter was found to be the most robust and reliable indicator of dark-induced hyperlocomotion. Qualitatively and quantitatively, the dark-induced increase in horizontal activity is similar to that seen after microinjection of DA into the medial posterior nucleus accumbens, but avoids the use of pharmacological agents that might directly interfere with synaptic release of the cotransmitters. As seen in Figure 5, the dark environment causes a greater amount of horizontal activity, significant in the first 10 min block of the 30 min test session. The pattern of greater activity during the first $10 \mathrm{~min}$ in the dark may be indicative of the less aversive nature of the novel open field when the open field is in the dark, as compared to when the open field is in the light, a phenomenon well characterized in several animal models of anxiety (Crawley, 1989a). One previous study with the darkinduced hyperlocomotion paradigm detected a decrease in darkinduced hyperlocomotion after microinjection of high doses of the nonselective CCK antagonist proglumide into the medial posterior nucleus accumbens (Crawley, 1988). The dark-induced hyperlocomotion paradigm was therefore chosen to evaluate the new, highly selective, potent CCK antagonists, in the medial posterior nucleus accumbens, anterior nucleus accumbens, and ventral tegmental area. Further, the three CCK antagonists were also administered systemically in the dark-induced hyperlocomotion paradigm, to determine the net effect of a CCK-A or CCK-B antagonist that might act simultaneously at several anatomical sites in the brain and periphery. Effects of systemically administered CCK antagonists in rats might be predictive of effects that would be obtained with these compounds administered systemically to humans.

L-364,718 had no effect on horizontal activity when administered intraperitoneally over a wide dose range $(100 \mathrm{ng} / \mathrm{kg}$ to $1 \mathrm{mg} / \mathrm{kg}$ ) in either the light or the dark environment. Similarly, CI-988 had no significant effect on horizontal activity when administered intraperitoneally at doses of $10 \mu \mathrm{g} / \mathrm{kg}$ or $1 \mathrm{mg} / \mathrm{kg}$, in either the light or the dark environment. L-365,260 treatment showed a significant decrease in horizontal activity at intraperitoneal doses of $10 \mathrm{ng} / \mathrm{kg}, 10 \mu \mathrm{g} / \mathrm{kg}$, and $1 \mathrm{mg} / \mathrm{kg}$, in the dark environment only. The decrease in exploratory activity at these intraperitoneal doses of L-365,260 may be meaningful, and requires further investigation. However, the lack of a dose-related function, the lack of effects of intracerebrally administered L365,260 , and previous reports that systemic L-365,260 increases rather than decreases motor activity in a feeding paradigm (Dourish et al., 1989) suggest that the present data may be artifactual. In particular, the highest dose of L-365,260 and L364,718 ( $1 \mathrm{mg} / \mathrm{kg}$ i.p.) had to be prepared in the $0.5 \%$ carboxymethylcellulose vehicle, which inhibited dark-induced hyperlocomotion when administered intraperitoneally alone (Fig. 6). Thus, behavioral effects shown for the dose of L-365,260 that produced the most significant decrease in horizontal activity in the dark may have been confounded by a vehicle effect. A similar trend was seen for reduced horizontal activity in the dark after L-364,718 (1 mg/kg i.p.) in $0.5 \%$ carboxymethylcellulose vehicle; however, this difference was not significant.

Systemic administration of CCK antagonists is likely to affect several anatomical sites simultaneously, possibly producing opposite effects at different sites, the sum of which might be zero. Since CCK produced qualitatively different modulatory effects on DA-induced changes in exploratory behavior in the medial posterior nucleus accumbens, as compared to the anterior nucleus accumbens, and as compared to the ventral tegmental area, it was possible that subtype-selective antagonists would differentially affect dark-induced hyperlocomotion at discrete anatomical sites. Microinjections into the medial posterior nucleus accumbens showed no effect of L-364,718, L-365,260, or CI988 , at the doses tested, on horizontal activity in either the light or the dark environment. Microinjections into the anterior nucleus accumbens showed no effect of CI-988, at the doses of 20 ng or $2 \mu \mathrm{g}$, on horizontal activity in either the light or the dark environment. Microinjections in the ventral tegmental area showed no effect of L-364,718, L-365,260, or CI-988, at the doses tested, on horizontal activity in either the light or the dark environment. These findings are in contradiction with the previous finding that high doses of proglumide, microinjected into the medial posterior nucleus accumbens, partially blocked darkinduced hyperlocomotion (Crawley, 1988). In the previous study, proglumide may have blocked dark-induced hyperlocomotion through a nonspecific, non-CCK receptor-mediated action. Alternatively, in the present study, insufficient doses of the selective CCK antagonists may have been used. Arguing against the latter interpretation are the data from Figures 2-4, demonstrating that the same doses of CCK antagonists effectively blocked the modulatory actions of exogenously administered CCK.

The lack of effect of CCK antagonists on a 15 min session of exploratory activity, and on a $\mathbf{3 0}$ min session of dark-induced hyperlocomotion, is consistent with the interpretation that endogenous CCK does not contribute to exploratory locomotion in the mesolimbic pathway. This finding may indicate that released endogenous CCK does not play a critical role in maintaining high levels of exploratory behaviors. Alternatively, the behavioral paradigms chosen for the present studies may not be sufficient to activate mesolimbic DA neurons to the extent required to release endogenous $\mathrm{CCK}$, according to the frequency coding hypothesis described above. In particular, the dark-induced hyperlocomotion paradigm may not be sufficiently activating to release endogenous CCK, or sufficiently sensitive to detect contributions of a small amount of released endogenous CCK. Further pharmacological characterization of the darkinduced hyperlocomotion paradigm, using $D_{1}$ and $D_{2}$ agonists and antagonists, may be necessary to determine the relative contribution of the mesolimbic pathway versus other neurotransmitter systems to dark-induced hyperlocomotion. Different behavioral paradigms may be necessary to detect measurable effects of CCK antagonists in the cell body or terminal field regions of the mesolimbic neurons in which CCK and DA coexist, to determine the role of endogenous $\mathrm{CCK}$ in the behavioral output of the mesolimbic system. In vivo studies of co-release of CCK and DA may be a useful approach to address these issues.

In conclusion, highly selective CCK antagonists block the modulatory actions of exogenously administered CCK on exploratory locomotor behavior, differentially at discrete anatomical sites. The CCK-A antagonist L-364,718 effectively blocked the ability of CCK to potentiate DA-induced hyperlocomotion in the medial posterior nucleus accumbens. The CCK-B antagonist CI-988 effectively blocked the ability of CCK to inhibit DA-induced hyperlocomotion in the anterior nucleus accumbens. The CCK-B antagonists L-365,260 and CI-988 effectively blocked the ability of CCK to potentiate DA-induced hypolocomotion in the ventral tegmental area. These findings are consistent with previous behavioral studies using subtype-selective CCK fragments, and with in vitro biochemical studies of CCK modulation of DA release from the anterior and posterior nu- 
cleus accumbens (Crawley et al., 1986; Vickroy et al., 1988; Altar and Boyar, 1989; Crawley, 1989b; Marshall et al., 1991). A CCK-B receptor subtype appears to mediate the actions of $\mathrm{CCK}$ in the anterior nucleus accumbens and ventral tegmental area, while a CCK-A receptor subtype appears to mediate the actions of $\mathrm{CCK}$ in the medial posterior nucleus accumbens. In addition, the present data provide information on active doses, vehicles, and routes of administration of the new CCK antagonists for future intracerebral microinjection studies. The recent availability of potent, subtype-selective, nonpeptide CCK antagonists raises the possibility of designing CCK-based drugs to treat disorders of dopaminergic function that are confined to specific sites within the mesolimbic pathway.

\section{References}

Adams CE, Fisher RS (1990) Sources of neostriatal cholecystokinin in the cat. J Comp Neurol 292:563-574.

Altar CA, Boyar WC (1989) Brain CCK-B receptors mediate the suppression of dopamine release by cholecystokinin. Brain Res 483:321 326.

Altar CA, Boyar WC, Oei E, Wood PL (1988) Cholecystokinin attenuates basal and drug-induced increases in limbic and striatal dopamine release. Brain Res 460:76-82.

Barrett RW, Steffey ME, Wolfram CAW (1989) Type-A cholecystokinin binding sites in cow brain: characterization using (-) [ $\left.{ }^{3} \mathrm{H}\right] \mathrm{L} 364718$ membrane binding assays. Mol Pharmacol 36:285-290.

Bartfai T, Iverfeldt K, Fisone G, Serfözö P (1988) Regulation of the release of coexisting neurotransmitters. Annu Rev Pharmacol Toxicol 28:285-310.

Britton DR, Yahiro L, Cullen MJ, Kerwin JF, Kopecka H, Nadzan AM (1989) Centrally administered CCK suppresses activity in mice by a peripheral-type CCK receptor. Pharmacol Biochem Behav 34:779783.

Brodie MS, Dunwiddie TV (1987) Cholecystokinin potentiates dopamine inhibition of mesencephalic dopamine neurons in vitro. Brain Res 425:106-113.

Burgunder JM, Young WS (1990) Ontogeny of tyrosine hydroxylase and cholecystokinin gene expression in the rat mesencephalon. Dev Brain Res 52:85-93.

Chang RSL, Lotti VJ (1986) Biochemical and pharmacological characterization of an extremely potent and selective nonpeptide cholecystokinin antagonist. Proc Natl Acad Sci USA 83:4923-4926.

Cottingham SL, Pickar D, Shimotake TK, Montpied P, Paul SM, Crawley JN (1990) Tyrosine hydroxylase and cholecystokinin mRNA levels in the substantia nigra, ventral tegmental area, and locus ceruleus are unaffected by acute and chronic haloperidol administration. Cell Mol Neurohiol 10:41-50.

Crawley JN (1988) Attenuation of dark-induced hyperlocomotion by a cholecystokinin antagonist in the nucleus accumbens. Brain Res 473:398-400

Crawley JN (1991) Cholecystokinin-dopamine interactions. Trends Pharmacol Sci 142:232-236.

Crawley JN (1989a) Animal models of anxiety. Curr Opin Psychiatry 2:773-776.

Crawley JN (1989b) Microinjection of cholecystokinin into the rat ventral tegmental area potentiates dopamine-induced hypolocomotion. Synapse 3:346-355.

Crawley JN, Davis LG (1982) Baseline exploratory activity predicts anxiolytic responsiveness to diazepam in five mouse strains. Brain Res Bull 8:609-612.

Crawley JN, Stivers JA, Blumstein LK, Paul SM (1985a) Cholecystokinin potentiates dopamine-mediated behaviors: evidence for modulation specific to a site of coexistence. J Neurosci 5:1972-1983.

Crawley JN, Hommer DW, Skirboll LK (1985b) Topographical analysis of nucleus accumbens sites at which cholecystokinin potentiates dopamine-induced hyperlocomotion. Brain Res 355:337-341.

Crawley JN, Stivers JA, Hommer DW, Skirboll LR, Paul SM (1986) Antagonists of central and peripheral behavioral actions of cholecystokinin octapeptide. J Pharmacol Exp Ther 236:320-330.

Dauge V, Steimes P, Derrien M, Beau N, Roques BP, Feger J (1989) CCK 8 effects on motivational and emotional states of rats involve
CCKA receptors of the postero-median part of the nucleus accumbens. Pharmacol Biochem Behav 34:157-163.

Dauge V, Bohme GA, Crawley JN, Durieux C, Stutzmann JM, Feger J, Blanchard JC, Roques BP (1990) Investigation of behavioral and electrophysiological responses induced by selective stimulation of CCKB receptors by using a new highly potent CCK analog: BC 264. Synapse 6:73-80.

Deutch AY, Cameron DS (1992) Pharmacological characterization of dopamine systems in the nucleus accumbens core and shell. Neuroscience 46:49-56.

De Witte P, Heibreder C, Roques B, Vanderhaeghen JJ (1987) Opposite effects of cholecystokinin octapeptide (CCK-8) and tetrapeptide (CCK-4) after injection into the caudal part of the nucleus accumbens or into its rostral part and the cerebral ventricles. Neurochem Int 10: 473-479.

Dourish CT, Rycroft W, Iversen SD (1989) Postponement of satiety by blockade of brain cholecystokinin $\left(\mathrm{CCK}_{\mathrm{B}}\right)$ receptors. Science 245 : 1509-1511.

Fallon JH, Hicks R, Loughlin SE (1983) The origin of cholecystokinin terminals in the basal forebrain of the rat: evidence from immunofluorescence and retrograde tracing. Neurosci Lett 37:29-35.

Freeman AS, Bunney BS (1987) Activity of A9 and A10 dopaminergic neurons in unrestrained rats: further characterization and effects of apomorphine and cholecystokinin. Brain Res 405:46-55.

Freeman AS, Chiodo LA (1988) Electrophysiological effects of cholecystokinin octapeptide on identified rat nigrostriatal dopaminergic neurons. Brain Res 436:266-274.

Graham WC, Hill DR, Woodruff GN, Sambrook MA, Crossman AR (1991) Reduction of ${ }^{125}$ I-Bolton Hunter CCK8 and ${ }^{3} \mathrm{H}-\mathrm{MK}-329$ (devazepide) binding to CCK receptors in the substantia nigra/VTA complex and its forebrain projection areas following MPTP-induced hemi-Parkinsonism in the monkey. Neurosci Lett 131:129-134.

Heimer L, Zahm DS, Churchill L, Kalivas PW, Wohltmann C (1991) Specificity in the projection patterns of accumbal core and shell in the rat. Neuroscience 41:89-125.

Hill DR, Campbell NJ, Shaw TM, Woodruff GN (1987) Autoradiographic localization and biochemical characterization of peripheral type CCK receptors in rat CNS using highly selective non-peptide CCK antagonists. J Neurosci 7:2967-2976.

Hill DR, Shaw TM, Graham W, Woodruff GN (1990) Autoradiographical detection of cholecystokinin-A receptors in primate brain using ${ }^{125} \mathrm{I}-\mathrm{B}$ olton Hunter CCK-8 and ${ }^{3} \mathrm{H}-\mathrm{MK}-329$. J Neurosci 10: 1070-1081.

Hökfelt T, Rehfeld JF, Skirboll L, Ivemark B, Goldstein M, Markey K (1980a) Evidence for coexistence of dopamine and CCK in mesolimbic neurons. Nature 285:476-478.

Hökfelt T, Skirboll L, Rehfeld JF, Goldstein M, Markey K, Dann O (1980b) A subpopulation of mesencephalic dopamine neurons projecting to limbic areas contains a cholecystokinin-like peptide: evidence from immunohistochemistry combined with retrograde tracing. Neuroscience 5:2093-2124.

Hökfelt T, Skirboll L, Everitt B, Meister B, Brownstein M, Jacobs T, Faden A, Kuga S, Goldstein M, Markstein R, Dockray G, Rehfeld J (1985) Distribution of cholccystokinin-likc immunoreactivity in the nervous system. In: Neuronal cholecystokinin (Vanderhaeghen JJ, Crawley JN, eds), pp 255-274. New York: New York Academy of Sciences.

Hökfelt T, Herrera-Marschitz M, Seroogy K, Ju G, Staines WA, Holets V, Schalling M, Ungerstedt U, Post C, Rehfeld JF, Frey P, Fischer J, Dockray G, Hamaoka T, Walsh JH, Goldstein M (1988) Immunocytochemical studies on cholecystokinin (CCK)-immunoreactive neurons in the rat using sequence specific antisera and with special reference to the caudate nucleus and primary sensory neurons. J Chem Neuroanat 1:11-52.

Hommer DW, Skirboll LR (1983) Cholecystokinin-like peptides potentiate apomorphine-induced inhibition of dopamine neurons. Eur J Pharmacol 91:151-152.

Hommer DW, Palkovits M, Crawley JN, Paul SM, Skirboll LR (1985) Cholecystokinin-induced excitation in the substantia nigra: evidence for peripheral and central components. J Neurosci 5:1387-1392.

Hommer DW, Stoner G, Crawley JN, Paul SM, Skirboll LR (1986) Cholecystokinin-dopamine coexistence: electrophysiological actions corresponding to cholecystokinin receptor subtype. J Neurosci 6:30393043.

Hughes J, Boden P, Costall B, Domeney A, Kelly E, Horwell DC, Hunter 
JC, Pinnock RD, Woodruff GN (1990) Development of a class of selective cholecystokinin type $B$ receptor antagonists having potent anxiolytic activity. Proc Natl Acad Sci USA 87:6728-6732.

Ingram SM, Krause RG, Baldino F, Skeen I C, I ewis MF, (1989) Neuronal localization of cholecystokinin mRNA in the rat brain by using in situ hybridization histochemistry. J Comp Neurol 287:260-272.

Jayaraman A, Nishimori T, Dobner P, Uhl GR (1990) Cholecystokinin and neurotensin mRNAs are differentially expressed in subnuclei of the ventral tegmental area. J Comp Neurol 296:291-302.

Khosla S, Crawley JN (1988) Potency of L-364,718 as an antagonist of the behavioral effects of peripherally administered cholecystokinin. Life Sci 42:153-159.

Lotti VJ, Chang RSL (1989) A new potent and selective non-peptide gastrin antagonist and brain cholecystokinin receptor (CCK-B) ligand: L-365,260. Eur J Pharmacol 162:273-280.

Marley PD, Emson PC, Rehfeld JF (1982) Effect of 6-hydroxydopamine lesions of the medial forebrain bundle on the distribution of cholecystokinin in rat forebrain. Brain Res 252:382-385.

Marshall FH, Barnes S, Hughes J, Woodruff GN, Hunter JC (1991) Cholecystokinin modulates the release of dopamine from the anterior and posterior nucleus accumbens by two different mechanisms. $J$ Neurochem 10:3695-3700.

Meyer DK, Beinfeld MC, Oertel WH, Brownstein MJ (1982) Origin of the cholecystokinin-containing fibers in the rat caudatoputamen. Science 215:187-188.

Moran TH, Robinson PH, Goldrich MS, McHugh PR (1986) Two brain cholecystokinin receptors: implications for behavioral actions. Brain Res 362:175-179.

Palacios JM, Savasta M, Mengod G (1989) Does cholecystokinin colocalize with dopamine in the human substantia nigra? Brain Res 488: 369-375.

Paxinos G, Watson C (1986) The rat brain in stereotaxic coordinates New York: Academic.

Peleprat D, Broer Y, Studler JM, Peschanski M, Tassin JP, Glowinski J, Rostene W, Roques BP (1987) Autoradiography of CCK receptors in the rat brain using [ $\left.{ }^{3} \mathrm{H}\right] \mathrm{Boc}\left[\mathrm{Nle}^{28,31}\right] \mathrm{CCK}_{27-33}$ and [ $\left.{ }^{125} \mathrm{I}\right] \mathrm{Bolton}-\mathrm{Hun}-$ ter $\mathrm{CCK}_{8}$. Functional significance of subregional distributions. Neurochem Int 87:495-508.

Pullen RGL, Hodgson OJ (1987) Penetration of diazepam and the non-peptide CCK antagonist, L-364,718, into rat brain. J Pharm Pharmacol 39:863-864

Rovati LC, Makovec F (1988) New pentanoic acid derivatives with potent CCK antagonistic properties: different activity on the periphery vs. central nervous system. In: Cholecystokinin antagonists (RY Wang, R Schoenfeld, eds), pp 1-11. New York: Liss.

Savasta M, Ruberte E, Palacios JM, Mengod G (1989) The colocalization of cholecystokinin and tyrosine hydroxylase mRNAs in mesencephalic dopaminergic neurons in the rat brain examined by in situ hybridization. Neuroscience 29:363-369.

Schalling M, Friberg K, Seroogy K, Riederer P, Bird E, Schiffmann SN, Mailleux P, Vanderhaeghen JJ, Kuga S, Goldstein M, Kitahama K, Luppi PH, Jouvet M, Hökfelt T (1990) Analysis of expression of cholecystokinin in dopamine cells in the ventral mesencephalon of several species and in humans with schizophrenia. Proc Natl Acad Sci USA 87:8427-8431.
Schiffmann SN, Vanderhaeghen JJ (1991) Distribution of cells containing mRNA encoding cholecystokinin in the rat central nervous system. J Comp Neurol 304:219-223.

Serongy KB, Dangaran K, Lim S, Haycock JW, Fallon JF (1989a) Ventral mesencephalic neurons containing both cholecystokinin- and tyrosine hydroxylase-like immunoreactivities project to forebrain regions. J Comp Neurol 279:397-414.

Seroogy K, Schalling M, Brene S, Dagerlind A, Chai SY, Hökfelt T, Persson H, Brownstein M, Huan R, Dixon J, Filer D, Schlessinger D, Goldstein M (1989b) Cholecystokinin and tyrosine hydroxylase messenger RNAs in neurons of rat mesencephalon: peptide/monoamine coexistence studies using in situ hybridization combined with immunocytochemistry. Exp Brain Res 74:149-162.

Skirboll LR, Grace AA, Hommer DW, Rehfeld J, Goldstein M, Hökfelt T, Bunney BS (1981) Peptide-monoamine coexistence: studies of the actions of cholecystokinin-like peptide on the electrical activity of midbrain dopamine neurons. Neuroscience 6:2111-2124.

Stittsworth JD, Mueller AI, (1990) Cholecystokinin octapeptide potentiates the inhibitory response mediated by $D_{2}$ dopamine receptors in slices of the ventral tegmental area of the brain in the rat. Neuropharmacology 29:119-127.

Studler JM, Simon H, Cesselin F, Legrand JC, Glowinski J, Tassin JP (1981) Biochemical investigation on the localization of cholecystokinin octapeptide in dopaminergic neurons originating from the ventral tegmental area of the rat. Neuropeptides 2:131-139.

Vaccarino FJ, Rankin J (1989) Nucleus accumbens cholecystokinin (CCK) can either attenuate or potentiate amphetamine-induced locomotor activity: evidence for rostral-caudal differences in accumbens CCK function. Behav Neurosci 103:831-836.

Vaccarino FJ, Vaccarino AL (1989) Antagonism of cholecystokinin function in the rostral and caudal nucleus accumbens: differential effects on brain stimulation reward. Neurossi Iett 97:151-156.

Vickroy TW, Bianchi BR, Kerwin JF, Kopecka H, Nadzan AM (1988) Evidence that type A CCK receptors facilitate dopamine efflux in rat brain. Eur J Pharmacol 152:371-372

Wang RY, Kasser RJ, Hu XT (1988) Cholecystokinin receptor subtypes in the rat nucleus accumbens. In: Cholecystokinin antagonists (RY Wang, R Schoenfeld, eds), pp 199-215. New York: Liss.

Weiss F, Tanzer DJ, Ettenberg A (1988) Opposite actions of CCK-8 on amphetamine-induced hyperlocomotion and stereotypy following intracerebroventricular and intra-accumbens injections in rats. Pharmacol Biochem Behav 30:309-317.

White FJ, Wang RY (1984) Interactions of cholecystokinin octapeptide and dopamine on nucleus accumbens neurons. Brain Res 300: 161-166.

Widerlov E, Kalivas PW, Lewis MH, Prange AJ, Breese GR (1983) Influence of cholecystokinin on central monoaminergic pathways. Regul Pept 6:99-109.

Yim CC, Mogenson GJ (1991) Electrophysiological evidence of modulatory interaction between dopamine and cholecystokinin in the nucleus accumbens. Brain Res 541:12-20.

Zhang J, Chiodo LA, Freeman AS (1991) Effects of the CCK-A receptor antagonist CR 1409 on the activity of rat midbrain dopamine neurons. Peptides 12:339-343. 